\title{
Deliberative Dialogues: Deontic Turn-taking and Illocutionary Acts
}

\author{
Cristina Corredor
}

Department of Philosophy, University of Valladolid, Spain

Copyright $\mathrm{O} 2018$ by authors, all rights reserved. Authors agree that this article remains permanently open access under the terms of the Creative Commons Attribution License 4.0 International License

\begin{abstract}
In deliberation, the participants' goal is to reach a common conclusion on the best available course of action. The aim of this contribution is to study some deontic aspects that characterize deliberative dialogues as a dialogical (and dialectical) practice. In particular, my exploration is an attempt to consider the way in which deliberation dialogues are structured by virtue of the obligations (commitments, duties) and rights (entitlements, authorizations) that participants assign and recognize each other, on the basis of their performed speech acts. Taking a point of departure in the Austinian approach to speech acts, I will contend that these normative positions, mutually recognized, contribute to determine the illocutionary effect of the utterances and thus the particular speech acts performed in the dialogue. Before that, I will suggest that the proposed claim put forward in a deliberative dialogue can be seen as a verdictive speech act, in that a proposal issues a practical judgement and commits the proponent to giving reasons in support of it. Moreover, whenever an agreement is reached on a proposed claim for action, a new exercitive speech act can be said to have been instituted in which the participants' joint commitment not only concerns the proposal agreed upon, but also the reasons given and the inferential license that connects both.
\end{abstract}

Keywords Deliberation, Deliberative Dialogue, Speech Acts, Proposal, Turn-taking, Austin, Illocutionary Effect

\section{Introduction}

According to some dialogical approaches to the study of deliberation, the goal of the dialogue is that the participants agree on the best available course of action for implementation. To this, it can be added that deliberation as a communicative practice is intrinsically subject to procedural requirements, in a way that group conversations or even public debates are not. Yet the existence of a certain procedure regulating the participants' turns does not completely determine the illocutionary force and meaning effectively attained by a particular utterance (cf. Sacks, Schegloff and Jefferson [6], Schegloff [8]). According to some speech-act theoreticians, an utterance in context usually conveys a potential of illocutionary forces, and each speech act creates a space of possibilities of appropriate response speech acts (Searle [9]). In the particular case of deliberation dialogues, my suggestion is that the interlocutors' response shows how the utterance has been taken and thus contributes to determine the illocutionary effect (pragmatic force) that a particular utterance has had in the interaction, provided that this response can be seen as appropriate to the final speech act. Moreover, I suggest that these patterns of initiation-response turns can be analysed taking into account the normative positions (commitments and entitlements, obligations and rights, etc.) mutually assigned and recognized by the interactants.

As a point of departure, deliberation is a dialectical and pre-eminently dialogical communicative practice, in which the discussion is directed at the common goal of reaching a joint decision on the best available course of action. Within the framework of dialogical approaches to the study of argumentation (Krabbe and Walton [4], Walton [12]), deliberation is characterized for the following features: (i) it departs from an initial situation in which there is a need for action; (ii) the relationship among participants is collaborative; (iii) the goal of any participant is to coordinate goals and actions; and finally, (iv) the goal of the dialogue is that the participants agree on the best available course of action for implementation.

There seems to be a general consensus among scholars in considering that the speech act of making a proposal must be seen as a defining feature of this type of dialogue and is necessarily present, as a first response to the envisaged situation and a starting point. Here, a proposal is understood as a claim of the form "We should do $A$ " or "Action $A$ should be carried out". Moreover, the fact that it is put forward as the opening illocution of a deliberation dialogue entails that it is open to the critical assessment of other participants. To that extent, an analysis of the role of 
proposals in deliberation can (and should) be distinguished of the more general notion of proposal that is available in informal and conversational settings, where other forms of interaction will be in place.

As already mentioned, deliberation can be taken to be a dialectical procedure, in that it involves doubts and objections and usually different arguments, pro and contra, in respect to a proposed claim. A deliberative dialogue, furthermore, involves turn-taking verbal exchanges between pairs of interlocutors ${ }^{1}$. In what follows, I will take it that deliberative dialogues are both dialectical and dialogical. Moreover, as I will contend below, they also are an argumentative practice.

\section{Plan}

In what follows, the methodology will be the usual one in Philosophy, namely, conceptual analysis and the critical examination of the arguments for and against the advanced standpoints. As a point of departure, I will take into consideration some well-established views in the realms of the theory of argumentation and the study of deliberation. In particular, I will endorse Krabbe's and Walton's notion of deliberation [4], as well as Toulmin's concept of argument [11]. Moreover, I will endorse the Austinian view on speech acts, as originally presented by Austin [1] and further developed by Sbisà [7]. Section 3 is devoted to an original analysis of the speech act of putting forward a proposal that I take to be in line with the Austinian framework. In section 4, I analyse the dynamics of deliberative dialogues in general, extending the Austinian framework to give account of this dynamics. Here, the methodology not only relies on conceptual analysis but also on a pre-understanding of the practice itself of deliberating with others, and some basic intuitions concerning this practice. In section 5 , two examples based on real deliberations are considered, both available in the literature on this topic. The analysis carried out in both cases is in line with the previously suggested theoretical account and, by means of illustration, aims to show how the suggested framework can be applied in actual deliberative settings. Finally, section 6 offers some concluding remarks.

\section{The Speech Act of Making a Proposal in Deliberation. Analysis and Suggestion}

My suggestion is that, within a deliberation dialogue,

\footnotetext{
${ }^{1}$ I am following here Blair's [3, p.10] suggested understanding of the terms 'dialectical' and 'dialogical' as applied to properties of arguments. My own suggestion is that deliberative dialogues, as a type of argumentative practice, answer to both characterizations.
}

proposals be seen a subtype of verdictive speech acts. The notion of a verdictive was originally introduced by Austin [1]. Taking his framework into account, it is possible to consider the speech act of making a proposal to be performed in accordance with a conventional procedure, having a conventional effect on the normative positions of the participants. Moreover, it is associated to a limited array of possible responses (invited responses in Austin's terms). Austin in his turn did not explicitly discussed the speech act of making a proposal but put forward a tentative taxonomy of types of speech act that, notwithstanding its shortcomings, is helpful and can be taken into consideration. Remember that, according to him, a verdictive is typified as the act of giving a verdict or finding, formal or informal, final or provisory, "upon evidence or reasons as to value or fact" ([1], pp. 150, 152). In her reworking of this notion, Sbisà has proposed that verdictives be characterized by the following interactional effects:

"A speaker performing verdictives in an interactional situation such as a public debate presents him or herself as willing to take on responsibility for the correctness of his or her claims and as acting on the basis of some kind of reliable and testable cognitive competence. The audience is supposed not merely to acquire the speaker's findings, but also some of his or her evidence or reasons and thereby of his or her competence." ([7], p. 167)

In my view, this nicely accounts for both the speaker's commitment concerning her carrying the burden of proof in making a proposal, as well as for the respondent's license or entitlement to ask for such justification. Although there must be willingness from the part of the speaker to undertake the justificatory obligation, according to Sbisà's Austinian approach the interactants' deontic stances is a conventional effect of the interaction in virtue of the interactants' agreement that their deontic stances have correspondingly changed. This strongly suggests that the obligation to justify can be seen as a conventional effect that characterizes and constitutes verdictive speech acts, without a need to postulate that this obligation is created by the speaker's aims and intentions.

To give support to the view that proposals in deliberation can be seen as a sub-type of verdictive speech act of the kind here considered, notice that making a proposal must be seen as a reasonable move in the deliberative dialogue. Therefore, the speaker can be legitimately expected to have some reasons to think that the proposal is/might be an appropriate answer to the situation. The proposal assigns to the other participants a right to put forward their doubts, objections, criticisms, and alternative proposals. Correspondingly, the proposal commits the speaker to providing reasons in support of it, and also to accept (and answer to) the criticisms, doubts, alternative suggestions, etc. of other participants. Moreover, if a participant rejects 
the proposal, this amounts to shifting the burden of proof onto him, who is then obliged to justify his rejection (or leave the deliberation). Thus this analysis makes explicit the normative stances (commitments, rights, etc.) that the participants in the deliberation dialogue recognize and assign each other whenever a proposal is put forward and duly dealt with.

Just for the sake of illustration, consider two people, A and $\mathrm{B}$, who work together and attempt to agree on the best date for holding an informal meeting. A says, "I think the best option is Friday in the afternoon, let's say at 2.30. Usually, there are no other meetings held and both of us will be available". B replies, "Friday afternoon? Fridays, we are busy trying to finish our respective pending tasks". Then A concedes, "You are right, then what about Thursday at the same time?" In this short exchange, A acts as proponent, putting forward a first suggestion and duly giving a reason to support it. B expresses a reservation which directly counterweighs A's adduced reason. In answer, A recognizes the force in B's reservation and makes a new proposal that meets this challenge. With her initial proposal, a not only redeems her duty to give support to it, but also her commitment to take into account and duly respond to B. In his turn, B not only expresses his reservation, but also gives a reason in support of it, thus reedeming in his turn his argumentative duty and 1 making it possible for A to counterbalance both reasons. These moves result in a reformulation of the initial proposal.

Nevertheless, the account of the speech act of making a proposal as a verdictive does not explain the effect that the proposal has, whenever accepted, in committing both the proponent and the respondent to a particular course of action, thus assigning them an obligation mutually recognized. If the respondent accepts the proposal, he can act so because he accepts the speaker's authority (case a) or because (case b) the reasons given are convincing for him. In the first case, my suggestion is that the addressee's response is decisive for the utterance to become an exercitive speech act (case a). In Austin's original characterization, an exercitive is "the giving of a decision in favor of or against a certain course of action, or advocacy of it. It is a decision that something is to be so, as distinct from a judgment that it is so: it is advocacy that it should be so, as opposed to an estimate that it is so (...)" ([1], p. 154) Notice that this kind of assignment of illocutionary force to the speech act should end up the deliberation dialogue. The same result of ending up deliberation would have the case in which the respondent accepts the proposal for the reasons put forward in the deliberation process (case b). Nevertheless, this is a case in which the respondent has acquired not only a commitment with a course of action, but also part of the speaker's reasons and thus of her competency. In this case, my suggestion is that the initial proposal qua verdictive has given place to a new speech act ${ }^{2}$, namely, a commissive that commits both proponent and respondent to the jointly agreed course of action.

Coming back to the previous example of A and B's exchange imagine that A is B's supervisor. Now, after she has proposed, "I think the best option is Friday in the afternoon, let's say at 2.30", B accepts immediately, without even waiting for any reasons in support of the suggestion. This would correspond to (case a), where the proponent's authority, as recognized by her interlocutor, does not lead the way to a joint deliberation. A different situation would be one in which B, after A's reformulation of her initial proposal, agrees by saying, "Ok, then let's meet Thursday at 2.30". Here, both interlocutors have reach an agreement on a common course of action, an agreement based on their joint consideration of reasons for and against a first, dismissed proposal. This last situation would correspond to (case b).

To give further support to the suggestion that making a proposal should be seen as a sub-type of verdictive, I suggest considering the way in which verdictives can entail a commitment not only to their justification, but also to certain course of action. According to Austin,

"verdictives commit us to actions in two ways: (a) to those necessary for consistency with and support of our verdict, (b) to those that may be, or may be involved in, the consequences of a verdict." ([1], p. 158).

In the particular case of proposals, given that they usually take the form of a practical ought-sentence, it seems reasonable to think that both effects can legitimately be expected to take place. Moreover, both are to be seen as conventional, since both types of commitment are constituted by the participants' mutual recognition and agreement that they are in force.

Now, it is possible to envisage an analysis of the dynamics of speech in deliberative dialogues, focusing on the way in which the final force of a speech act is party fixed by the participants' response.

\section{The Dynamics of Speech in Deliberative Dialogues. Analysis and Provisional Results}

Usually, in a deliberative dialogue at least two roles can be identified, namely, those of proponent and respondent.

2 I am thankful to Prof. Anne Bezuidenhout for suggesting to me the idea that, in the situation here considered a new speech act was performed (oral communication). My initial view on the matter was that a change in the force of the speech act was effected in virtue of the addressees' response. I think that the final account here assumed, which follows her suggestion, nicely agrees with the Austinian framework. Moreover, it allows an explanation of how future revisions of the initial proposal can be carried out, which would be based on the reasons for its adoption and not on features of the commitment undertaken. 
In group deliberation, these roles can shift from one participant to another, and can be undertaken for more than one person. Still, deliberation is subject to procedural requirements that mere group conversations or even public debates do not need. This feature, the existence of a certain procedure regulating the participants' turns, can be taken as decisive for the determination of the illocution effectively performed by means of a certain utterance, in ways to be clarified below. In conversational exchanges in general, I take it that a speaker's utterance can typically receive a number of different interpretations from an addressee, a circumstance that leaves open what illocution has effectively been performed. Here, the addressee's reception can select one of those possible interpretations, thus being determinative of the illocution effectively performed, and this precisely in virtue of their recognizing its performance.

Yet in informal conversational dialogues, many utterances can be left without an explicit reception or sequel, which seems to amount to an under-determination of the speech act performed. This effect can increase with the number of interactants, since there seems to be no principled reason preventing them from opting for different interpretations among the available ones. In public debates, in contrast, the participants' reception can be and usually is manifested through their interventions, in a way that can help determine the form in which the speaker's utterance is being taken. As Sbisà has argued, in public debates "the audience's questions and comments are a source of illocutionary force selection for at least some parts of a speaker's talk" ([7], p. 17). It is to be expected that in deliberative dialogues, this process of selection of the illocutionary force of an utterance by the interactants' manifested reception acquires a more definite, precise ordering and explicitness.

\subsection{Turn-taking in Deliberative Dialogues}

Considering the pattern of turn-taking that is in force, when a speaker makes a proposal for action in a deliberative setting, together with her initial turn a set of possible moves become available to the other participants. From the point of view of the deliberative procedure that is taking place, the respondent's move can be of direct acceptance, but he also can express doubts and request justification; he can raise objections and present a rebuttal; he can express partial acceptance, suggesting corrections or reformulations, and finally he can reject the proposal. Each of these communicative moves entails different commitments or obligations and rights or entitlements for the participants. Consider, for instance, the case in which the respondent raises an objection or expresses doubts. This move amounts to asking for justification, as in the case above seen. However, to the extent that a rebuttal or an objection is to be seen itself as a verdictive, the objector can be requested by the proponent (or some other participant) to better justify his speech act, a situation that should have the effect of shifting the burden of proof onto him. The same shifting of the burden of proof can take effect if the respondent rejects the proposal and the proponent, or any other of the participants, asks him to justify his move. However, if the respondent suggests some corrections or reformulation, it is the turn of the proponent to give an answer to the suggestion (either accepting it, rejecting it, asking for clarification, or suggesting further reformulations, etc.) Still, a participant different from the first proponent can make an alternative proposal, thus making room for a set of different moves which may include a comparison of both proposals as based in previous evaluations by the participants.

What I have suggested in the preceding paragraphs can be better developed and systematized as follows. Whenever a speaker makes a proposal for action in a deliberative setting, her speech acts licenses a set of possible moves from the participants:

1. manifest direct acceptance

2. express doubt and request justification

3. raise objections and present rebuttals

4. express partial acceptance, suggesting corrections or reformulations

5. reject the proposal

6. put forward a different proposal

These different moves amount to a set of patterns of initiation-response that entail different assignments of duties, rights, etc. among participants. In particular, the following situations, at least, can be distinguished.

1. The respondent manifests direct acceptance. Then the situation amounts to cases (a) and (b) above, with the respective normative roles already suggested.

2. The respondent expresses doubt and requests justification. This assigns the proponent an obligation to fulfil her commitment to justify.

3. The respondent raises objections and presents rebuttals. This can give place to two different situations:

- The respondent's intervention can amount to asking for justification, thus assigning the proponent this obligation (as in 2).

- But the respondent can also be requested to better justify his speech act, a situation that should have the effect of provisionally shifting the burden of proof onto him (thus assigning him an obligation)

4. The respondent suggests some corrections or reformulation (his right). Then, it is the turn of the proponent to give an answer to the suggestions (this obligation is assigned to her), but she can fulfil this obligation in a set of different forms: either accepting them, or rejecting them, asking for clarification, and suggesting further reformulations. 
5. The respondent rejects the proposal (his right) and the proponent asks him to justify his move (her right). Here, also a shifting of the burden of proof takes effect on the respondent (assigning him an obligation)

6. A participant different from the first proponent puts forward an alternative proposal (their right). This generates a set of different possibilities, since a set of different moves are available to the participants. These may include a comparison of both proposals, as based in previous and new evaluations by the participants. Consequently, the move confers the right to participate in this way, and assigns a justificatory obligation in such a case.

In each of these cases, I have argued that certain patterns are in force, guiding the participants in addressing one another as the person who carries the obligation to justify his or her move. The deliberative dialogue will proceed as long as the participants undertake their respective obligations and rights, prominently the obligation to justify and the right to ask for justification, until a collective decision is taken on the basis of an agreement or (as it may be the case) the procedure is closed without their having been able to reach a common decision on the discussed course of action. It is worth noticing that these patterns are not limited to, nor always prompted by the assignment of the burden of proof to the participant who performs a verdictive. In the case in which a participant raises an objection to the proponent's proposal, at least two moves are available. The proponent can choose to try and answer to the objection, giving further support to her speech act; but alternatively, she can also ask the respondent to better explain or support his objection, a move with the effect of shifting the burden of justification to him.

Additionally, not all of these speech acts are verdictives. For instance, opting for one of two alternative proposals, and rejecting or voting for a proposal, are commisives (acts that "commit the speaker to a certain course of action", Austin [1], p. 156). And also certain moves can play the role of behabitives ([1], p. 159) ${ }^{3}$. Moreover, argumentation plays a decisive role in deliberative dialogues, and contributes to articulate the dynamics of the exchange.

\subsection{The Role of Argumentation in Deliberative Dialogues}

I endorse the view that arguing is a communicative practice consisting of speech act complexes. These are composed of two further acts, the act of adducing (reasons) and the act of concluding (a target claim) (Toulmin [11], Bermejo-Luque [2], p. 60). In line with the characterization of speech in terms of conventional patterns, I suggest

3 For a comprehensive view of the types of acts that can occur in deliberative dialogues, see McBurney et al. [5], pp. 100-101. viewing argumentation as a sequence where adducing (reasons) and concluding (a target claim) are constitutive parts of it, together with the (usually implicit) act of warranting that presents the former as giving support to, and thus licensing the move to the latter.

To have a hint of the way in which argumentation could be characterized as organized following turn-taking patterns, the following possible situation can be briefly considered. Suppose that a speaker gives a reason to support a proposal which becomes thus her supported target claim. The respondent is then allowed to perform a limited set of moves, some of which have already been mentioned. First, the respondent can accept the speaker's proposal, thus acquiring himself part of the speaker's competence and becoming therefore allowed to state other closely related claims. Second, he can reject the proposal, a move that should shift the burden of proof to him, thus assigning the respondent an argumentative obligation. Third, he can raise some doubts or objections, a move that can amount to stating a rebuttal. If this is the case, he can be said to be exercising a power or influence on the proponent, who has in her turn to undertake the obligation to solve the doubts or answer the objections. If the objections have the force of a rebuttal, according to Toulmin the warrant itself turns out to be questioned. The effect is then that the exercitive force of the warrant shifts and it becomes a (questioned) verdictive in need of further justification, thus assigning a renewed obligation to the proponent.

\section{Two Examples}

\subsection{No-fault Insurance}

Here I am borrowing and adapting an example of real deliberation presented in Walton et al. [13]. As the authors say, the example is that of a meeting convoked to make a decision on whether or not to bring in no-fault insurance ${ }^{4}$ in a state. The context is the following: "The problem to be addressed was the perception that insurance rates were so high that they had become burdensome for the average citizen in this state. The general perception was that this problem needed to be solved by changing to a no-fault system of auto insurance." ([13], pp. 11-13). The interventions can be schematized as follows:

Participant 1 (proponent): We should introduce no-fault insurance to reduce premiums. This will achieve the goal of premiums not being burdensome, promoting the value of affordability.

Participant 2: Introducing no-fault insurance would not reduce premiums since the ability to sue for pain and suffering will be left intact.

4 No-fault insurance, sometimes referred to as personal injury protection insurance (PIP), can help cover you and your passengers' medical expenses and loss of income in the event of a covered accident, regardless of who is found at fault. 
Participant 3: We should not introduce no-fault insurance since good drivers will pay for bad drivers. This would bring about cross-subsidization, demoting the value of fairness.

Participant 4: We should encourage competition to reduce premiums. This will achieve the goal of premiums not being burdensome, promoting the value of affordability.

Participant 5: When no-fault insurance was introduced in Location L premiums fell by $10 \%$.

The authors remark that Participant 5 rebuts Participant 2 , thus removing an obstacle for the proposal to become acceptable. Moreover, Participants 1, 3 and 4 are appealing to different values as reasons to support their respective claims. Therefore, a value-based argumentation scheme can be taken to represent their arguments. Finally, the authors also notice that Participant 4's reasons offer a way in which affordability (the value appealed to by the proponent) can be promoted without compromising fairness, since the argument is not attacked by Participant 3 . Taking this into consideration, they draw the conclusion that the rational decision for the participants would be to reject no-fault insurance and rely on competition to reduce premiums.

From the point of view of the interaction and the changes introduced in the respective normative positions of the participants, all of them are complying with their obligation to adduce reasons in support of their claims, even before this is required by another participant. This anticipation may be seen as a reasonable move within the dynamics of deliberation, given its goal of the participants' agreeing on a common decision based on the merits. Participant 1 , who acts as proponent, must be willing to listen to and take into consideration the other participants' doubts and objections, as well as their possible alternative proposals. Moreover, Participant 5's rebuttal should motivate Participant 2 to retract his or her claim, which is a move that not only Participant 2 but also the rest of them can legitimately expect.

Still, Participants 3 and 4 seem to appeal to different values, fairness and affordability, but they are not conflicting values. If another participant's proposal is in tune with their respective values, then the former may legitimately expect that the latter consider their adherence to it. An additional feature that seems to speak in favor of the solution proposed by Walton et al. (namely, that Participant 4's solution be agreed upon) is that Participant 4 is not only acting as antagonist (as Participant 3 does), but he or she is also putting forward a new proposal; moreover, he or she supports with reasons the way in which his or her solution promotes the value of affordability, which was in the opening stage of the deliberation the most detached common worry. In this way, Participant 4 is answering to the commitment of finding an answer to the question of how to act, in order to overcome the conflictive situation that all of them face.
If all the participants were to express their agreement with Participant 4's proposal, the claim would acquire the illocutionary force of an exercitive speech act, becoming a mandate as to how to act. If, in other case, another participant was to produce some evidence acting as a counterexample, then Participant 4 could legitimately be expected to retract his or her claim.

\subsection{Informed Consent in Biobank Research}

The second example to be considered here is from an article that presents results related to a real debate over the role of informed consent in biobank research (Secko et al. [10]). As the authors note, a point of contention was whether the significance of biobank research could outweigh a person's right to withdraw after consenting. This topic is common to the following interventions ${ }^{5}$.

Lisa: But we're affecting everything that they [biobank researchers] have put together and all the finances and all the energy that's been put into it... you're right, you have the right to leave, but ethically is that right for you to be able to do that? I don't think it's fair.

Julia: And then it's useless.

Lisa: And then it's useless and it's all for nothing.

[...]

Klass: I disagree with that because I think that things that seem quite obvious to us when we're young may seem completely different as we mature... so to say that something you decided when you were, say, 20, has to govern the way you're going to be positioned to work for the rest of your life, I can't see the advantage to that. I would say that consent could be withdrawn at any time.

[...]

Lisa: Could you do it on one consent form, and have the top section, Part A, say "I agree to have my sample tested under anything that falls under the biobank ethics board's regulations." Tick yes, tick no. And if you tick yes, you're good to go.

Klaas: Yeah.

[...]

Dennis: I think when we're talking consent we're talking about a whole range of approvals. And I suspect that there are different life experiences and there are different things you learn as you mature. I don't know if it's simply a factor of giving consent and withdrawing consent. You may pick one of the dots, one of the boxes along the way and say, "Okay, I now give half consent, or consent to these features, or blanket consent, or no consent."

Relevantly, the participants were able to reach some

5 For the sake of the illustration, here I select some of them, respecting the order but omitting some of the material; see [9], pp. 787-788. 
deliberative conclusions that were incorporated into a joint final report. These were,

"(1) the need to consider whether consent is needed for any and all uses of particular samples; (2) the need to examine whether donors could specify the conditions under which they provide samples; (3) persistent disagreement about adequacy of review and the need for consent for research that was not specified at initial consent." (Secko et al. [10], p. 788)

In the sequence, the initiator, Lisa, may be seen as the proponent. She supports a definite standpoint with respect to withdrawal after consenting ("I don't think it's fair"), and she fulfills her obligation to justify even before explicitly formulating the standpoint. The second participant, Julia, gives further support to this standpoint by adducing an additional reason ("And then it's useless") that is reiterated by Lisa, who in this way also endorses Julia's reason. As a result, both become committed to the expressed standpoint, and because of the reasons adduced. This move confers to other participants a right either to support the same standpoint, if they accept the reasons already given, or to question and try to rebut it, in case they see reasons against that have not been taken into account. The latter option is effected by Klass, who explicitly opens his intervention by declaring his opposition to the standpoint ("I disagree with that"), but immediately goes on to fulfill his obligation to justify his reluctance towards Lisa's and Julia's proposal (“... because...”). On account of the reasons given, a counter-proposal is stated, "I would say that consent could be withdrawn at any time"). Hence, the deliberative dialogue is here one in which two opposing proposals are being examined simultaneously. This feature together with the distinctive context, in which the deliberative dialogue is taking place, helps explain the participants' perceived need to support their interventions with reasons, thus fulfill their obligation to justify even before they have been requested to do so.

Interestingly, in her second intervention Lisa shows her willingness to take into account Klass's reasons against her initial proposal. She does it by suggesting a third, intermediate possibility between the two opposing standpoints. In this way, she is committing to revise her own standpoint in line with the suggestion. Klass's confirmatory answer shows his agreement with the line of revision initiated by Lisa, thus committing himself to accept such a reformulation. In the last intervention, Dennis further works out the details of the same line of revision and explicitates a proposal in a somewhat indirect way, by pointing out to a possible procedure. To the extent that he is taking into account both the reasons advanced by Klass and the line of revision initiated by Lisa, his elaboration of the proposal not only commits him, but also confers a right to both Klass and Lisa to critically examine whether or not Dennis's proposal answers to their concerns and, in such a case, the right to support it. It is worth noticing that the joint conclusions (1) and (2), as incorporated into the final joint report, nicely respond to this last formulation of the proposal. With their final report, the participants not only commit themselves to recommendations (1) and (2), which primarily should be taken to be exercitive speech acts. They also commit themselves to the reasons given in support of them and to the denial of the rejected options, also for the reasons given against. In respect to conclusion (3), however, no joint commitment has been attained, a situation that assigns the participants a right to still maintain their individual viewpoints on the matter.

\section{Concluding Remarks}

It is worth noticing that, in both examples 5.1 and 5.2, each participant's available moves have been constrained by the other participants' moves, in a way that entitles them to certain acceptable speech acts in the exchange, and also obliges them to certain others -as is the case of retracting a defeated claim (example 5.1), and of working out a revision of one's initial standpoint that takes into account the rebutting reasons adduced (example 5.2). Moreover, the illocutionary force initially assigned to an utterance can result in a new speech act with a different force, depending on the recognition afforded to it by the other participants. In example 5.1, an intended verdictive can become an unhappy one (if defeated by reasons), thus changing the commitments of its speaker and the legitimate expectations of the other participants. Also in this example, a verdictive put forward as a proposal can give rise to an exercitive, provided that the participants agree on it. In example 5.2, an initial proposal, qua verdictive, motivates a revision that ends up in a new proposal (another verdictive). Still, this revised proposal, in its turn, gives rise to a new speech act of recommendation (an exercitive) that also entails a commitment from the participants. This suggests that other possible moves by the participants would introduce new obligations and entitlements, thus instituting other possible speech acts.

To conclude, both the conceptual analysis carried out and the examples presented give support to the view that, firstly, deliberative dialogues can be described by saying how the participants' normative positions (obligations and commitments, entitlements and rights, etc.) change with the dialogue, and secondly, the force of the speech acts performed in the course of the dialogue is partly determined by the participants' (possibly tacit) recognition of the normative changes effected. This recognition does not need to take the form of an explicit agreement, but it is manifested in the participants' moves as the dialogue goes on. I would say that the most salient feature of deliberative dialogues is that, whenever the dialogue ends up in a joint agreement on a proposal for action, the participants' joint commitment not only concerns the proposal agreed upon, 
but also the reasons given in support of it, and the inferential license that connects both. This helps explain the revocability of the commitment, in case some of the reasons is afterwards seriously questioned.

\section{Acknowledgements}

This work has been funded by the Ministry of Economy and Competitiveness of the Government of Spain, research project FI2106-79317-P.

\section{REFERENCES}

[1] J.L. Austin. How to Do Things with Words. Oxford, Clarendon Press, 1962.

[2] L. Bermejo-Luque. Giving Reasons: A Linguistic-Pragmatic Approach to Argumentation Theory, Dordrecht, Springer, 2011.

[3] J. Anthony Blair, The Limits of the Dialogue Model of Argument, in: OSSA Conference Archive, Vol. 10, 1997. Available online at:

http://scholar.uwindsor.ca/ossaarchive/OSSA2/papersandco mmentaries/10, last accessed 05.12.2017.

[4] E. Krabbe and D. Walton. Commitment in Dialogue: Basic Concepts of Interpersonal Reasoning, New York, State University of New York Press, 1995.

[5] P. McBurney, D. Hitchcock, S. Parsons. The eightfold way of deliberation dialogue, International Journal of Intelligent Systems, Vol. 22, 95-132.

[6] H. Sacks, E. Schegloff and G. Jefferson. A simplest systematics for the organization of turn-taking for conversation, Language, Vol. 50, No. 4, Part 1, 696-735, 1974.

[7] M. Sbisà. Communicating citizenship in verbal interaction: principles of a speech act oriented discourse analysis, in: $\mathrm{H}$. Hausendorf and A. Bora (eds.), Analysing Citizenship Talk, Amsterdam, John Benjamins, 151-180, 2006.

[8] E. Schegloff. Sequence organization in interaction: a primer in conversation analysis I, Cambridge, Cambridge University Press, 2007.

[9] J.R. Searle. Speech Acts: An Essay in the Philosophy of Language, Cambridge, Mass., Cambridge University Press, 1969.

[10] D.M. Secko et al. Informed consent in biobank research: a deliberative approach to the debate, Social Science and Medicine, Vol. 68, 781-789, 2009.

[11] S. Toulmin. The Uses of Argument, Cambridge, Cambridge University Press, 1958 [Updated edition, 2003]

[12] D. Walton. How to make and defend a proposal in a deliberation dialogue, Artificial Intelligence and Law, Vol. 14, 177-239, 2006.

[13] D. Walton et al. 2010. Argumentation in the framework of deliberation dialogue, in: C. Bjola and M. Kornprobst (eds.), Arguing Global Governance, London, Routledge, 210-230, 2010. [Here quoted from the version online available at: http://www.dougwalton.ca/papers\%20in\%20pdf/10Delib.p df, last accessed 05.12.2017] 